\title{
Determination of the seismic signatures of landslides in soft soils: a methodology based on a field scale shear box
}

\author{
Yfantis, G. ${ }^{1}$, Pytharouli, S. ${ }^{1}{ }^{*}$, Lunn R.J. ${ }^{1}$ and Carvajal, H.E.M. ${ }^{2}$ \\ ${ }^{1}$ Department of Civil and Environmental Engineering, University of Strathclyde, Glasgow, \\ $U K$ \\ ${ }^{2}$ Department of Civil and Environmental Engineering, University of Brasilia \\ *Corresponding author: Stella Pytharouli (stella.pytharouli@strath.ac.uk)
}

Keywords: landslide monitoring; microseismic; field scale; shear box

\begin{abstract}
We present a novel field experimental setup that can be used for studying the characteristics of landslide seismicity. The setup consists of a concrete, filled with soil, cylinder that moves along a surficial soil corridor. The emitted seismic signals are due to soil friction. The cylinder acts as an upscaled sheer-box allowing control over a number of parameters: the magnitude of normal stress on the failure plane, the degree of saturation and the type of soil. This allows for the simulation of soil friction within, or between, different geological layers under different conditions. Results are site specific, but can be easily reproduced for any geological environment. We validate this methodology by comparing the spectral characteristics of the signals emitted by the movement of the cylinder to those induced by a controlled failure of a $2.5 \mathrm{~m}$ high vertical face at a nearby site with very similar geology. We find a very good agreement between the two. This methodology can be used as a site investigation tool for the optimization of the deployment geometry of seismic networks for landslide monitoring, as well as to inform machine learning algorithms on automatic detection and classification of recorded signals during seismic monitoring of landslides.
\end{abstract}

Keywords: field shear box, microseismic monitoring, landslides

\section{Introduction}

Extreme weather phenomena have more than doubled, even tripled at times, since 1980 (European Academies' Science Advisory Council, 2018). As a result, in 2018 only, flooding accounted for $39 \%$ of the reported natural disasters. This 
percentage becomes $5 \%$ in the case of landslides and soil mass movements (Ritchie and Roser, 2019). This number does not include incidents of landslides induced by flooding. Such events can cause major disruption including loss of human life (Petley, 2012) and great economic cost (Sassa and Canuti, 2009). Understanding and predicting the behaviour of landslides remains a major geotechnical challenge. In the past 15 years, passive seismic monitoring has been used systematically to detect, characterise and locate seismic waves induced by slope failure in an effort to better understand their kinematics. This type of monitoring is mainly common for slopes dominated geologically by rocks (e.g. Vilajosana et al., 2008; Barla et al, 2010; Helmstetter and Garambois, 2010; Gigli et al, 2011; Guinau et al., 2019): the rock's brittle behaviour translates to higher amounts of emitted seismic energy during failure when compared to soils. Soils have lower density and thus, high attenuation properties, which makes it difficult for weak seismic waves, such as those emitted during fissure formation, to be detected.

Current research on seismic monitoring of slopes and their potential failure focuses on identifying and categorizing seismic signals emitted as a result of fracture formation and soil movement, e.g. Hibert et al. 2014; Zimmer and Sitar, 2015; Provost et al,, 2018; Schöpa et al. 2018. A number of studies focus on reducing the errors involved in locating accurately such seismic sources, i.e. finding where the failure originated (e.g. Amitrano et al., 2010; Levy et al, 2011; Walter et al, 2011; Rothmund and Joswig, 2012). Seismic monitoring of landslides/rockslides involves seismometers being deployed around slopes prone to failure for time periods that could span from a few days to years (Walter et al,, 2011). All recorded signals need to be characterised and their sources identified. These sources include, among others, local, regional and teleseismic earthquakes, anthropogenic and environmental noise, etc. The different types of seismic sources are validated based on a priori knowledge of the area's seismicity and/or on other technologies, such as video recordings, piezometers, GNSS and total stations, which all contribute to the confirmation, location and origin time determination of landslide occurrences (Mainsant et al., 2012). This can be an expensive exercise. 
67 More recently, machine learning has been applied to the detection and classification of landslide/rockslide seismic recordings, e.g. Vouillamoz et al. (2018), Qu et al. (2019); Hibert et al. (2019). This approach, which originates from the field of signal processing, has been quite revolutionary, especially in the analysis of continuous, noisy seismic recordings. Hence, machine learning has been increasingly gaining recognition and momentum amongst researchers and professionals in the field. The caveat is that the effectiveness of such methodologies requires large sets of labelled seismic data from slope monitoring records to be used for training. Such data are sparse, and amongst those that are available to the scientific community, most are in Alpine environments, i.e. rockslides. Seismic data sets from landslides in soft soils are rare. To add to this, the seismic signatures of soil (and rock) failure depend on the geology encountered along the source-to-receiver (seismometer) path and the soil properties, both of which could differ for different areas with differing soil types.

We present an easy to implement methodology that helps fill this gap and could potentially be used to (1) develop a data-base of seismic signals induced by soil friction, specific for the site/area of interest. This data-base could then be used to inform automatic identification and classification algorithms. (2) Inform the optimisation of the geometry of the passive seismic monitoring network. Our novel experimental setup can simulate landslide originated seismic signals on site. The procedure allows for the control over the material type and properties of the simulated landslide, as well as its depth, to suit the needs of the area that is being monitored. The information deducted from the analysis of the collected data can be used for the identification of the frequency content and waveform pattern of the emitted signals, and the role of local geology, in the propagation of the seismic waves.

\section{Methods}

Experimental set-up overview: The experimental set-up is designed to induce displacement of one soil layer relative to another, thus reproducing the source mechanism, i.e. soil slip, along the failure plane of a landslide in soft soils. During such an event, friction between soil particles produces seismic waves that travel through the surrounding geology and are recorded by seismometers. The method 
uses an up-scaled shear box, which allows control over a number of parameters: the load applied, the induced stress (i.e. the magnitude of normal stress on the failure plane) and the depth of the failure plane.

A concrete hollow cylinder $(0.5 \mathrm{~m}$ high, $0.65 \mathrm{~m}$ internal diameter $)$ is filled with a $15 \mathrm{~cm}$ layer of compacted soil and a $35 \mathrm{~cm}$ layer of non-compacted soil. The cylinder is placed on top of a surficial soil corridor free from vegetation (Figure 1). The cylinder is connected to a reel via a high-tension manila rope and metallic chain and is pulled along the soil corridor. Movement occurs in "pulses": tension built up on the rope connecting the cylinder with the reel overcomes the resistance of static friction, then drops when the cylinder starts moving. We use concrete slabs to vary the load applied on the slip surface.

Detailed description of the experimental set-up: A list of all parts of the experimental set-up is provided below:

1. A concrete cylinder, $0.5 \mathrm{~m}$ high, with an external and internal diameter of $0.75 \mathrm{~m}$ and $0.65 \mathrm{~m}$ respectively.

2. A surficial soil corridor free from vegetation, $4 \mathrm{~m}$ long, $1.5 \mathrm{~m}$ wide. The dimensions of the corridor are chosen such that the concrete cylinder fits within the width of the corridor. It is desirable that the cylinder can move over a distance of at least 2 times the cylinder's diameter.

3. A $200 \mathrm{~mm}$ thick metallic plate placed on top of the cylinder (fig. 1). The plate has a $600 \mathrm{~mm}$ diameter (smaller than the internal diameter of the cylinder). The weight of the metallic plate used in this study was approximately $100 \mathrm{~kg}$.

4. 10 circular, $0.75 \mathrm{~m}$ diameter, $200 \mathrm{~mm}$ thickness concrete plates, each placed on top of the metallic plate (fig. 1). The weight of each concrete plate varied between 41 and $52 \mathrm{~kg}$ (see Table 1).

5. A manually operated reel.

6. A high-tension manila rope.

7. A high-tension steel chain.

8. 7 short period 3D Sercel seismometers, with a flat frequency response from $2 \mathrm{~Hz}$ to $100 \mathrm{~Hz}$.

9. 7 REFTEK dataloggers set to record continuously at $1000 \mathrm{~Hz}$ sampling rate. Synchronisation of the data loggers was achieved by the use of GPS. 
(a)

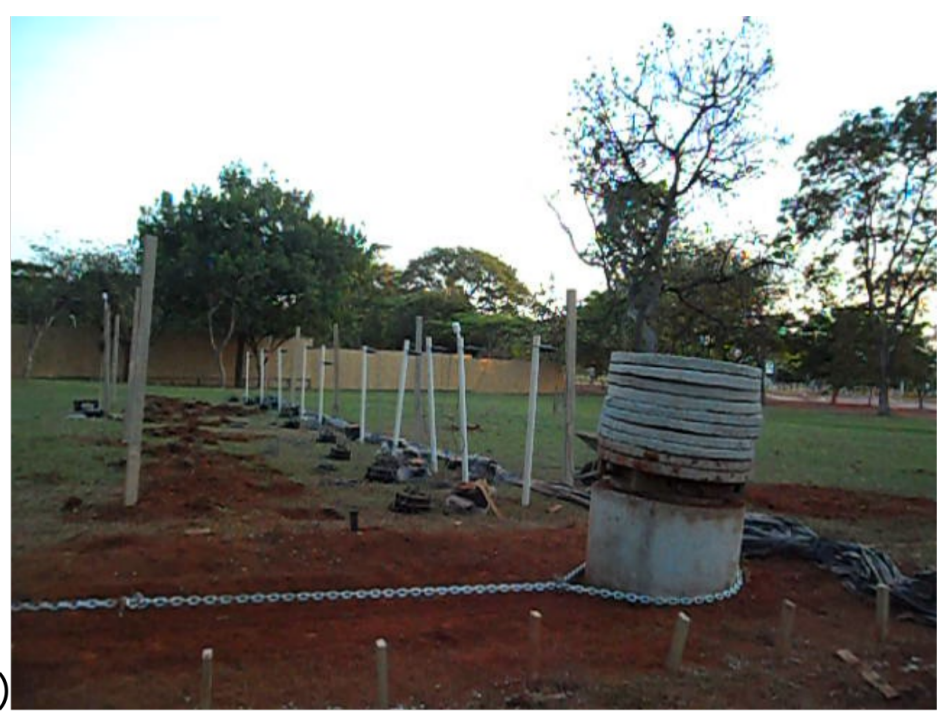

134

(b)

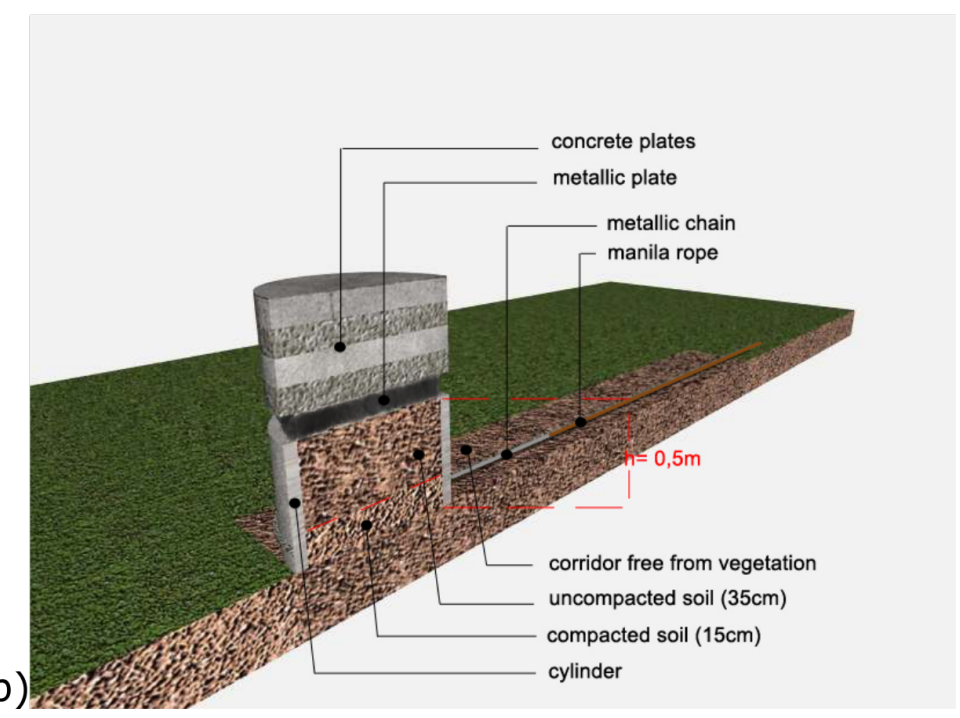
batteries (40Amp, 12Volt).
135

10. A power source for the data loggers and seismometers: in this case 7 car 
Table 1: Weight of the concrete plates used

\begin{tabular}{|l|l|l|l|}
\hline No of concrete plate & Weight (kg) & No of concrete plate & Weight (kg) \\
\hline $\mathbf{1}$ & 45 & $\mathbf{6}$ & 45 \\
\hline $\mathbf{2}$ & 49 & $\mathbf{7}$ & 41 \\
\hline $\mathbf{3}$ & 47 & $\mathbf{8}$ & 47 \\
\hline $\mathbf{4}$ & 47 & $\mathbf{9}$ & 41 \\
\hline $\mathbf{5}$ & 52 & $\mathbf{1 0}$ & 42 \\
\hline
\end{tabular}

141

The first step in setting up the experiment is to construct a surficial soil corridor free from vegetation without disturbing the natural compaction state of the soil. The concrete cylinder is then placed on the corridor.

A layer of soil, $15 \mathrm{~cm}$ thick, is placed inside the cylinder and is compacted using the standard proctor rules (Smith, 1981) in order to match the compaction stage of the surficial soil. This creates an interface between the surficial soil along the corridor and the compacted soil layer inside the cylinder. The soil placed inside the cylinder is taken from the top layer of the site under investigation, excavated on the day of the experiment. This is important in order for the two soil layers that are in contact to share the same mechanical properties. The remaining empty space to the top of the cylinder is then filled with non-compacted soil from the site. This soil acts as an overweight, increasing the stress levels on the interface between the soil of the surficial corridor and the soil inside the cylinder.

The metallic plate is placed on top of the cylinder's soil (inside the cylinder), followed by the concrete plates. Together, they control the stress levels on the surface between the soil in the cylinder and the corridor. The concrete plates are not in contact with the cylinder. They are supported solely by the metallic plate. This ensures that the soil carries the full load of the plates and that no load is carried by the cylinder itself (fig. 1b).

The cylinder is connected to a reel (fig. 2) using a steel chain and a manila rope tied together, both capable of enduring high levels of tension. The chain has a stable, easily adjustable hold on the concrete cylinder (fig. 1a). If the chain is tied around the reel's drum, the small impacts and friction between the chain and the drum or the chain itself could add to the seismic noise. To avoid this, a manila rope is tied around the reel's drum creating a smooth interaction surface between the 
chain and the drum. The chain is then tied to the manila rope (fig. 2). The reel needs to be stabilised. In our case, stabilization of the reel was achieved by burying its two legs $\sim 0.5 \mathrm{~m}$ into the soil and by fastening it onto a tree.

Our monitoring system consisted of 7 three-component short period seismometers buried $0.5 \mathrm{~m}$ below surface to minimize noise and maximise the coupling between the sensor and the soil. Each sensor had its own datalogger, GPS clock and battery to minimize data loss in case of random instrumental failures and to ensure synchronisation of all recordings. Sensors were deployed along a line perpendicular to the cylinder's movement direction as shown in Figure 3. The two horizontal components were aligned towards North-South and East-West directions, respectively.

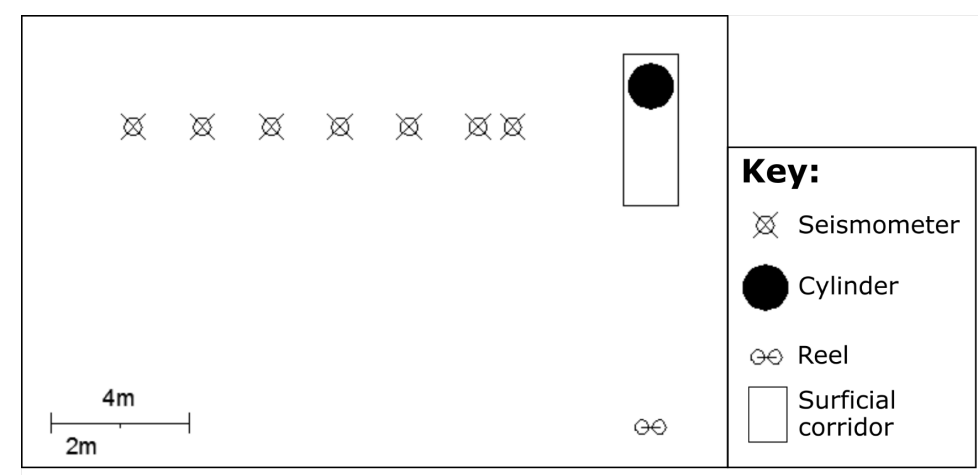

Figure 2. Plan view of experimental set up.

The source-to-receiver distances (cylinder $\equiv$ source, seismometer $\equiv$ receiver) were $4 \mathrm{~m}, 5 \mathrm{~m}, 7 \mathrm{~m}, 9 \mathrm{~m}, 11 \mathrm{~m}, 13 \mathrm{~m}$, and $15 \mathrm{~m}$ away from the centre of the surficial corridor. This dense linear deployment geometry was designed to ensure a low detection threshold, i.e. recording of the smallest displacements of the cylinder and to allow for a detailed analysis of the emitted seismic signals as they propagated away from their source.

The seismometers were constantly deployed throughout the experiment and set to a continuous acquisition mode. Our test site was in the city of Brasilia (Brazil) close to the city centre. To reduce noise from day-to-day activities all experiments took place early in the morning: all experiments were carried out between 05:00 and 06:45, with each experiment lasting no more than 5 minutes. Background 
191

192

193

194

195

196

197

198

199

200

201

202

203

204

205

206

207

208

209

210

211

212

213

214

215

216

217

218

219

noise was recorded for 1 hour in total prior to the experiments, as well as for 1 minute before and after each experiment. We ensured the same monitoring conditions for all recordings, including no changes to the levelling or orientation of the seismometers.

It was important (1) to investigate whether signals generated by soil displacements could be detected above noise levels, and (2) to determine whether recordings with high signal-to-noise ratios could be produced close to urban areas, proving that seismometers can be realistically used as a monitoring method for landslides in such environments.

Experiments: Four experiments were carried out, each under a different loading (and stress) condition: Experiment 1: 472kg (14.03kPa), Experiment 2: $568 \mathrm{~kg}$ $(16.88 \mathrm{kPa})$, Experiment 3: 743kg (22.09kPa), Experiment 4: 829kg $(24.64 \mathrm{kPa})$. These loads include the weight of the concrete slabs and the weight of the soil within the cylinder. The stress is controlled by adding or reducing load (i.e. concrete slabs) on top of the soil in the cylinder. Load, force and stress levels on the slip surface, as well as an equivalent depth of the events if they were to occur on a slope, are shown in Table 2. The stress and equivalent depth were calculated using equations (1) to (4) (Craig, 2004):

$\mathrm{F}=\mathrm{m} \times \mathrm{g}$

(eq. 1)

$\sigma_{\mathrm{v}}=\gamma_{\text {soil }} \times \mathrm{Z} \quad$ (eq. 2 )

$\sigma_{\mathrm{v}}=\mathrm{F} /$ Sarea $\quad$ (eq. 3 )

combining equations (1) to (3) we get:

$\mathrm{z}=(\mathrm{F} /$ Sarea $) / \gamma_{\text {soil }} \quad$ (eq. 4$)$

where $\mathrm{F}$ is the force $(\mathrm{N})$ applied on area $\mathrm{S}_{\text {area }}\left(\mathrm{m}^{2}\right)$ of the soil surface in the cylinder, $g$ is the acceleration of gravity $\left(\mathrm{m} / \mathrm{sec}^{2}\right), \sigma_{\mathrm{v}}$ is the vertical stress $\left(\mathrm{kN} / \mathrm{m}^{2}\right)$ at depth $\mathrm{z}(\mathrm{m})$ and $\gamma_{\text {soil }}$ is the unit weight $\left(\mathrm{kN} / \mathrm{m}^{3}\right)$ of soil.

For our experimental set-up, $S_{\text {area }}=\pi \times(0.65 / 2)^{2}=0.33 \mathrm{~m}^{2}, \gamma_{\text {soil }}=18 \mathrm{kN} / \mathrm{m}^{3}$. 
Table 2: Load, force, stress levels and equivalent depth of a failure plane for all 4 experiments. Calculation of the force, stress and equivalent depth was based on equations (1) - (4).

\begin{tabular}{|c|c|c|c|c|}
\hline $\begin{array}{c}\text { Experiment } \\
\text { number }\end{array}$ & $\begin{array}{c}\text { Applied load } \\
\text { (kg) }\end{array}$ & $\begin{array}{c}\text { Applied } \\
\text { force (kN) }\end{array}$ & $\begin{array}{c}\text { Applied } \\
\text { stress (kPa) }\end{array}$ & $\begin{array}{c}\text { Equivalent } \\
\text { depth for a } \\
\text { failure plane } \\
\text { (m) }\end{array}$ \\
\hline $\mathbf{1}$ & 472 & 4.63 & 14.03 & 0.78 \\
\hline $\mathbf{2}$ & 568 & 5.57 & 16.88 & 0.94 \\
\hline $\mathbf{3}$ & 743 & 7.29 & 22.09 & 1.23 \\
\hline $\mathbf{4}$ & 829 & 8.13 & 24.64 & 1.37 \\
\hline
\end{tabular}

Experimental procedure:

Step 1: Recording of background seismic noise. At least one hour of continuous noise recordings is required for the characterisation of the general background noise.

Step 2: Each Experiment starts by recording one minute of background noise measurements as additional noise recordings from Step 1.

Step 3: The soil-filled concrete cylinder is pulled along the surficial corridor with the use of a reel. Tension is gradually built on the manila rope as the reel's arm is slowly turned. This tension is transmitted to the steel chain and eventually to the concrete cylinder. During this process, the manila rope is undergoing small deformations. When this tension overcomes the resistance of static friction between the soil layer within the cylinder and the surficial soil of the corridor, the cylinder moves.

Step 4: As the cylinder starts moving, the state of stress and deformation of rope is gradually restored. Meanwhile, the tension forcing the cylinder to move reduces until it is smaller than the friction resisting the cylinder's movement. At that point, the cylinder stops moving. The displacement of the cylinder is in the range of a few centimetres at a time, with the actual movement less than 1-2 seconds. Steps 3 and 4 are schematically shown in Figure 3. Steps 3 and 4 are repeated until the cylinder is displaced more than a meter in total. This is to allow multiple cylinder slip events to occur under the same experimental conditions resulting in a large database of seismic recordings. 
247

248

249

250

251

252

253

254

255

256

257

258

259

260

261

262

263

264

265

266

267

268

269

270

271

272

273

274

275

276

277

278

Step 5: Upon completion of Step 4, one minute of seismic background noise is recorded and the experiment is complete.

If more than a metre distance is left between the cylinder and the end of the corridor, a new experiment could start with different parameters, e.g. a different load on top of the cylinder. Otherwise, the cylinder is pulled back to the beginning of the corridor and Steps 1-5 are repeated for the next Experiment.

It should be noted that during the induced slip events, the concrete cylinder is in contact with the soil. The friction between concrete and soil is expected to also emit seismicity but it can be considered a trivial addition to the seismic energy released due to the slip of the two soil layers. Two arguments support this. (1) The self-weight of the concrete cylinder is very small compared to the sum of weight of the soil within the cylinder and the weight of the concrete slabs, and (2) the area of the concrete cylinder that is in contact with the soil corridor is very small compared to the corresponding area of the soil within the cylinder.

\section{Analysis of recordings:}

The analysis was carried out in the frequency domain and was based on the algorithm proposed by Welch (1967) and the calculation of power spectral density (PSD) (Press et al., 1992). We also carried out a time-frequency analysis for the whole duration of each Experiment to confirm whether the frequency content of the slip events of the same Experiment was similar: We make the assumption that all events were considered to emit similar seismic signals, as long as the experimental conditions (i.e. loading conditions on the slip surface and degree of saturation of soil) were kept constant. This assumption allowed for the calculation of the PSD and identification of the recorded signal frequency content, using more than one slip events. All PSDs of the soil slip events induced within the same experiment were taken into account for the creation of a single averaged PSD curve. The spectrograms for the time-frequency domain analysis were based on Short Time Fourier Transforms (Press et al., 1992). All computations were carried out in Matlab. The start and end time of all Experiments was known from the experimental procedure and the field log kept during all Experiments. This allowed for the identification and isolation of the parts of the seismograms 
containing the signals emitted as a result of the cylinder movement along the corridor. Multiple displacement events (corresponding to multiple cylinder movements along the corridor) were induced during the duration of each Experiment. These events were similar but not exactly identical (see figure 4 for the recordings of Experiment 1 over time).

a.

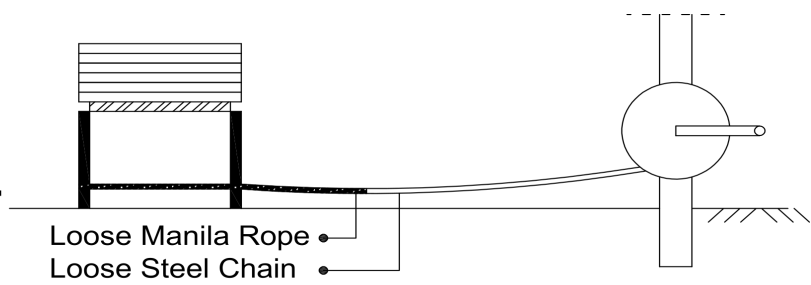

b.

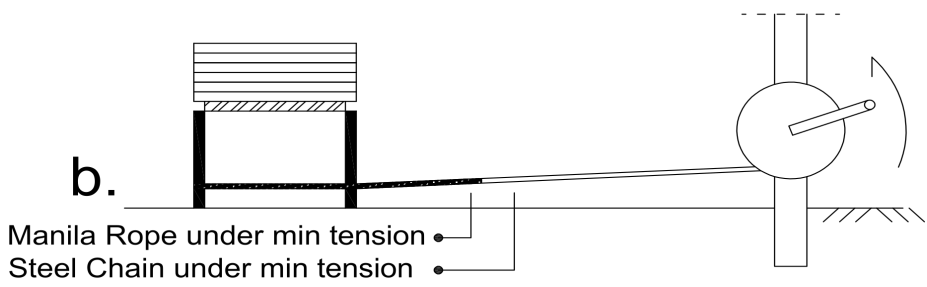

C.

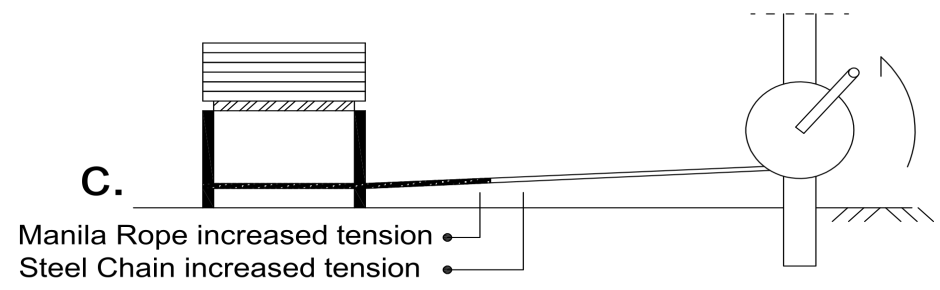
Steel Chain increased tension

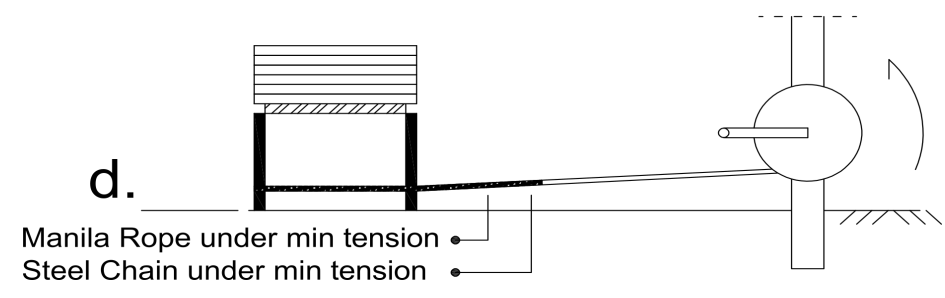

Figure 3. Simulation of a slip event mechanism using an up-scaled shear box experimental procedure: a) A cylinder filled with soil is connected to a reel with a loose steel chain and a manila rope; no tension is applied. b) The arm of the reel is turned creating a tension level capable of lifting the weight of both the steel chain and manila rope and stretching them. c) The arm of the reel is turned more, thus increasing the tension on the steel chain and manila rope. The manila rope is now undergoing small deformations. The static friction developed on the slip surface between the soil within the cylinder and the surficial corridor is preventing the cylinder from moving. d) The static friction of the slip surface between the soil 
(a)
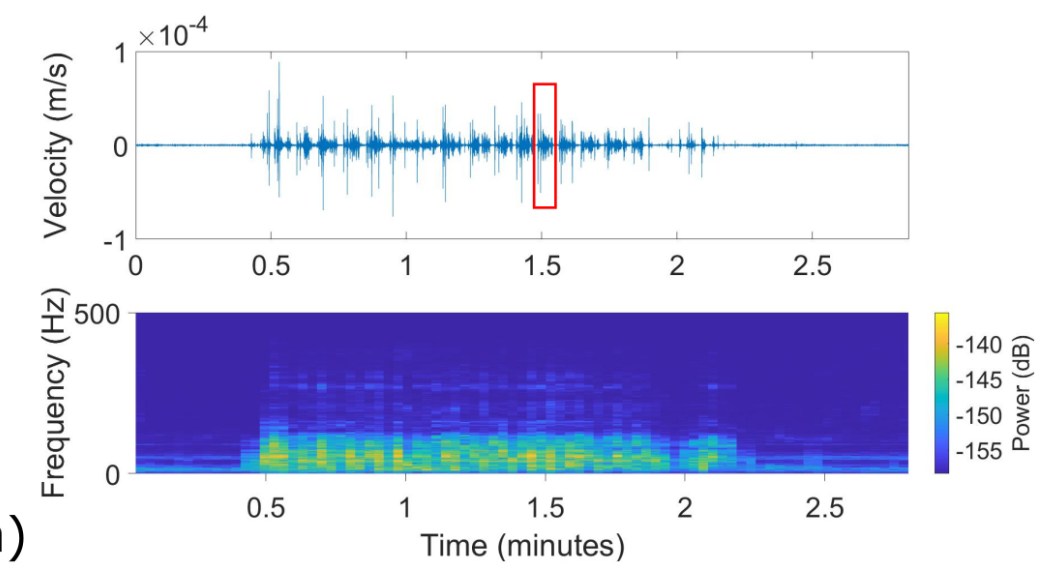

297

within the cylinder and the surficial corridor is smaller than the tension developed on the steel chain and the manila rope, thus allowing the cylinder to move.

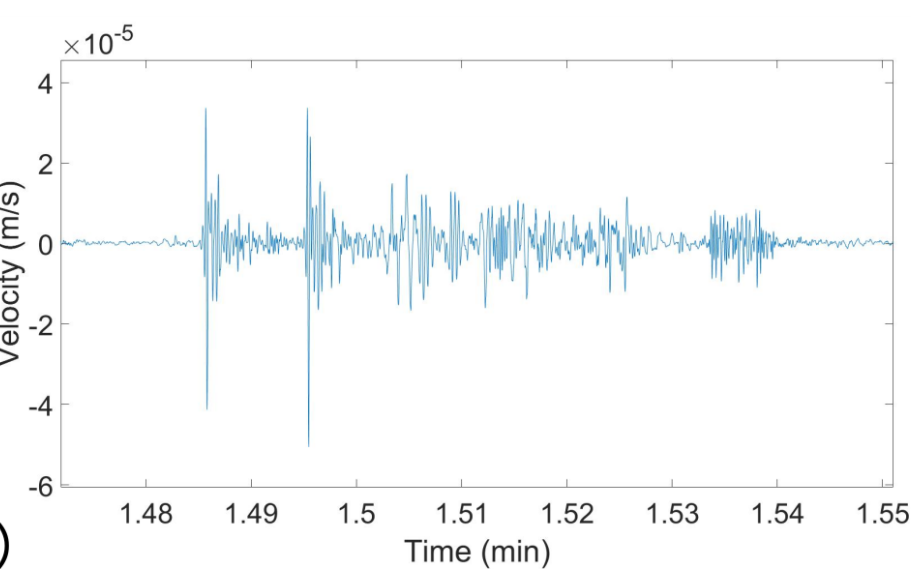

\section{(b)}

Figure 4. (a) top: Raw velocity data over the full duration of Experiment 1. (a) bottom: corresponding spectrogram of recordings. It can be seen that the frequency content of the different slip events is very similar. (b) Zoomed in part of the recordings within the red rectangle area in (a) showing a slip event, i.e. from start to end of a single cylinder movement.

They ranged from abrupt short displacement events to slower continuous movements. The latter is associated with the mechanism of raising tension in the manilla rope, resulting in slightly different slip events along the corridor. The slip event peak amplitudes ranged from $7 \times 10^{-6} \mathrm{~m} / \mathrm{sec}$ for Experiment 1 to $5 \times 10^{-4}$ $\mathrm{m} / \mathrm{sec}$ for Experiment 4, as recorded by the seismometer that was at $4 \mathrm{~m}$ distance from the cylinder. The standard deviation of the background seismic noise levels was $2.27 \times 10^{-6} \mathrm{~m} / \mathrm{s}$. In between each slip event the cylinder was immobile. During 
those time segments, seismometers were recording just ambient noise. These noise recordings were of different time length. The latter, along with the different number of slip events recorded at each experiment, led to a different ratio between the noise and the signal time duration that was recorded for each of the four different Experiments. In order to be able to directly compare the frequency analysis results from the different experiments, the ratio between the noise and the signal time duration needed to be kept constant. We achieved this following the methodology described in Yfantis (2015, p. 74) and briefly summarised in the following 4 stages: i) The total duration of the noise recordings in between slip events was calculated for each Experiment. ii) The experiment with the maximum total noise duration was identified. iii) The experiment identified in (ii) was truncated at the start of the first slip event to the end of the last slip event and the ratio between the signal and noise durations was calculated. iv) The other three Experiments were truncated keeping a noise segment before and after their first and last slip events, respectively, with duration such that it matches the signal to noise duration ratio identified in (ii).

\section{Results}

Relationship between emitted energy and loading: Figure 5 shows the PSD spectra of the data recorded from the vertical component of the seismometers deployed at $4 \mathrm{~m}$ and $15 \mathrm{~m}$ away from the cylinder (source) during all four Experiments. The dotted curve in all plots is the average PSD curve of all recorded background noise data. The area below each PSD curve is representative of the emitted energy. All loading conditions resulted in signals well above the background noise levels. From Figure 5 it can be shown that the PSD spectra of the signals from all Experiments share a similar pattern, i.e., the change in stress does not change the frequency content of the recordings, but it does affect the actual value of the PSD: the higher the stress, the higher the value of the resulting PSD amplitude. This is expected, as a higher stress results in a higher degree of friction and therefore, the release of more energy when this friction is overcome. Extrapolating this result to real landslides we would expect that landslides with deeper failure planes should induce seismic signals with larger amplitudes during a failure along these planes. However, this stands only in cases where the energy attenuation through the soil 
342 is significantly smaller compared to the total amount of energy emitted during 343 failure. The frequency content of those recorded pulses that greatly exceed noise 344 levels was found to be mainly below $120 \mathrm{~Hz}$ (Figure 5), a result that agrees with 345 other findings on soft soil landslides (Walter and Joswig, 2008). Small differences 346 between the frequency content of the data recorded at different distances away 347 from the cylinder can be attributed to the attenuation during wave propagation 348 through the soil.

349 Relationship between emitted energy and source-to-receiver distance: Figure 6 350 shows the PSD spectra of the data recorded from the vertical component of the 351 seismometers during Experiment 1 (472kg load) at four different distances. This 352 experiment was chosen as a representative case with results being the same for 353 the other loads. 


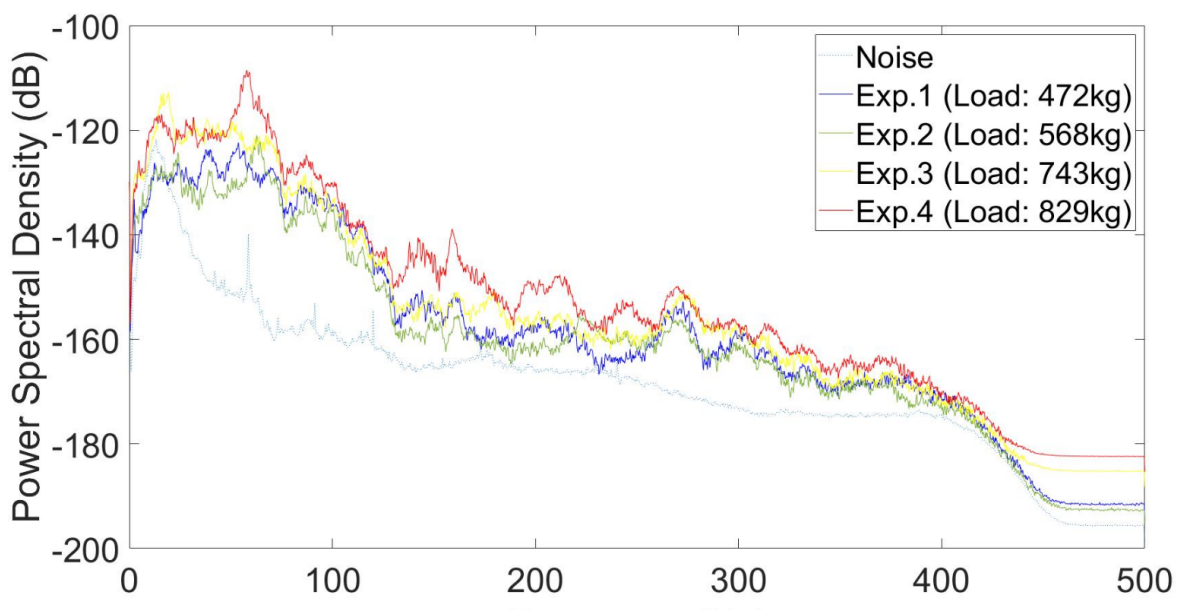

(a)

Frequency $(\mathrm{Hz})$

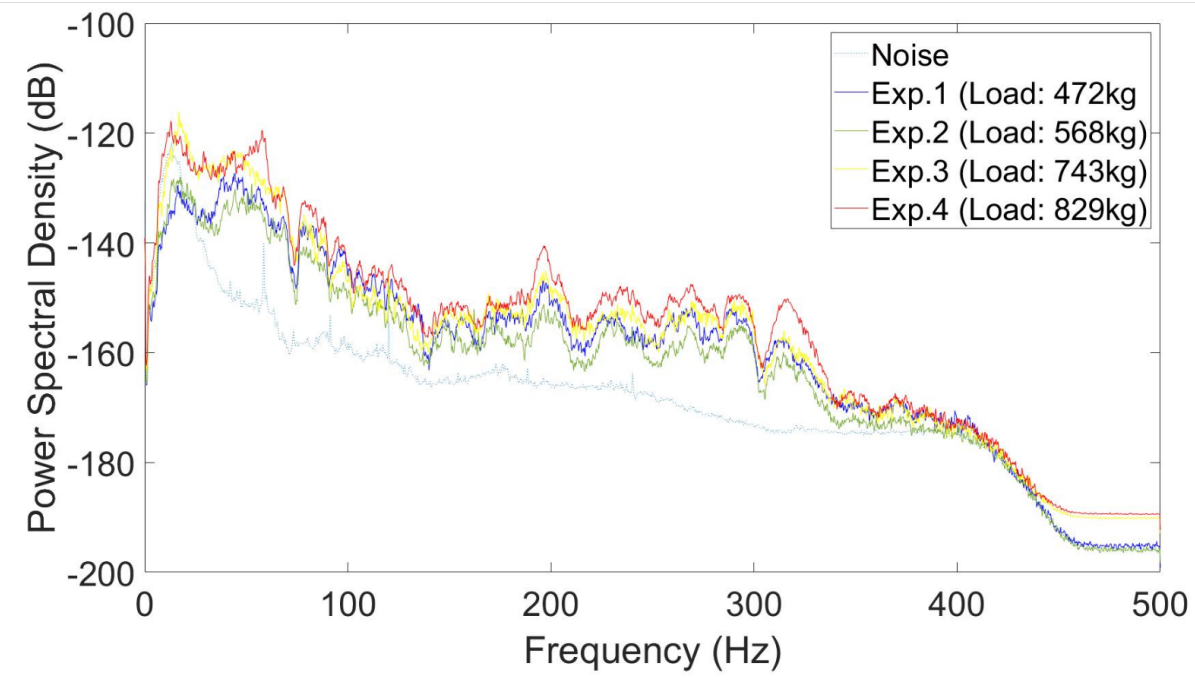

355 Figure 5: PSD spectra of the data recorded by the vertical component of the seismometers for all four experiments at a) $4 \mathrm{~m}$ and b) $15 \mathrm{~m}$ away from the cylinder (source). The PSD spectra of noise is the average PSD product of all noise recordings from the vertical component. 


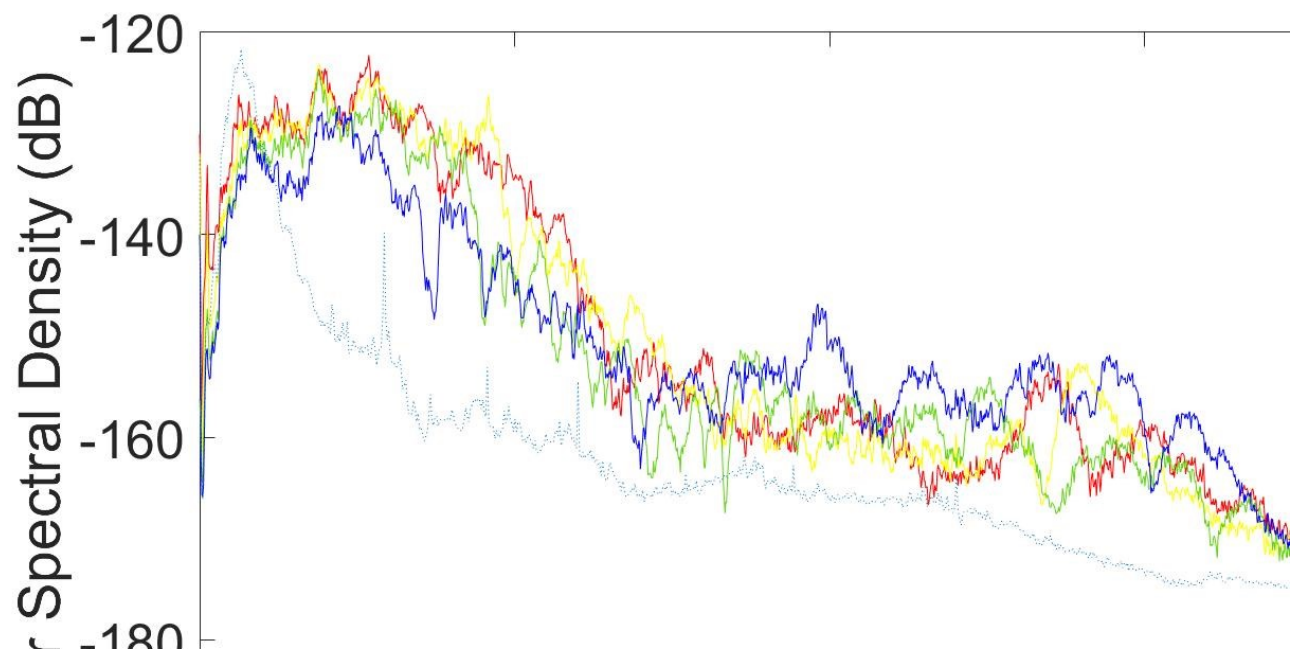

361

362

363

364

365

366

367

368

369

370

371

372

373

374

375

376

377

378

379

380

381

382

Figure 6: Experiment 1 - PSDs of data from the vertical component of the deployed seismometers at source-to-receiver distances of $4 \mathrm{~m}, 7 \mathrm{~m}, 11 \mathrm{~m}$ and $15 \mathrm{~m}$. The dashed blue curve is an averaged PSD curve from all background noise recordings of all seismometers.

The larger the source-to-sensor distance, the lower the resulting PSD value (Figure 6), evidence that the energy contained in the emitted signals is dissipated as the signal travels from the source towards the sensor (attenuation effect). This is observed in the PSD spectra of all sensors for all Experiments. The data can then be used to understand the attenuation of the seismic energy of a landslide, a very important parameter when it comes to designing the deployment geometry of the seismic monitoring network.

\section{Discussion}

In order to validate the assumption that the methodology described above is a good analogue for landslide-induced seismic signals, we compare our findings from Experiment 4 (equivalent depth of failure plane at $1.37 \mathrm{~m}$ ), with those of seismic signals recorded during an induced failure, under controlled conditions, of a $2.5 \mathrm{~m}$ high vertical face at a nearby site with similar geology (Yfantis et al., 2013, Yfantis 2015; Yfantis et al. - under revision). The recordings and results from the analysis are directly comparable as both the geological and loading conditions are similar, the instrumentation used for monitoring is the same and the source-tosensor distances are similar ( $9 \mathrm{~m}$ for Experiment 4 and $10 \mathrm{~m}$ for the vertical face). During the induced failure of the $2.5 \mathrm{~m}$ vertical face, different types of failure 
383

384

385

386

387

388

389

390

391

392

393

394

395

396

397

398

399

400

401

402

403

404

405

406

407

408

409

410

411

412

413

414

events were observed. These included: soil block topple and fall and soil block fall. The first, involved toppling and falling as well as shear within the soil mass, with the failure plane being almost the full height of the vertical face (around $2 \mathrm{~m}$ ). The second involved having parts of the vertical face falling down with the failure mechanism being mainly shear (Yfantis, 2015; Yfantis et al. under revision). Figure 7 summarises the results. All PSD spectra are above the background noise level. All spectra are similar in pattern, amplitude and frequencies. However, some differences are evident. More specifically, for the $2.5 \mathrm{~m}$ vertical face a) there are peaks between frequencies $25 \mathrm{~Hz}$ and $32 \mathrm{~Hz}$ at the PSD curve, b) there is a trough between frequencies $45 \mathrm{~Hz}$ and $70 \mathrm{~Hz}$. c) the rate of energy loss is almost constant for frequencies above $70 \mathrm{~Hz}$ for the soil block topple and fall failures (I and II), while for the soil block fall (III) the rate of energy loss is higher between 70 and $130 \mathrm{~Hz}$. In the cylinder experiment the PSD curve shows a sharp drop around $70 \mathrm{~Hz}$ where the loss of energy is rather sharp but the rate of energy loss slows down after $130 \mathrm{~Hz}$.

The differences between the spectra from the cylinder experiment and the vertical face can be attributed to three main factors: (1) The vertical face had a more complex failure mode, consisting of a combination of soil friction, soil block toppling and soil impact at the foot of the slope (Yfantis 2015), compared to Experiment 4, which is only soil friction along with some soil displaced in front of the cylinder (as the latter was pulled along the corridor). This is also evident from the higher similarity between the spectrum of Experiment 4 and that from the soil block fall (vertical face III in Figure 7), where friction was the main factor for both. Soil impact is also present for the soil block fall, but because previous failures had occurred, the fall height was significantly smaller and the impact was on pre-existing unconsolidated failed soil. (2) The induced failure of the vertical face took place at a different site. Although both sites share similar geological characteristics, small differences between them are expected due to soil heterogeneities. (3) Small variations in background noise levels over time could affect the spectra of the signals as some noise is inevitably included in the calculations. In addition, the volume of the failed mass affects the spectrum. This can be seen when comparing the spectra of the two soil block topple and fall 
failures (I and II in Figure 7). Slight differences can be seen despite the fact that the failure mechanism, the field site and the instrumentation were the same. However, because the two failures happened with approximately 1.5 minutes' time difference, it is possible that the background noise had slightly changed. Also, the two failures involved slightly different soil volumes.

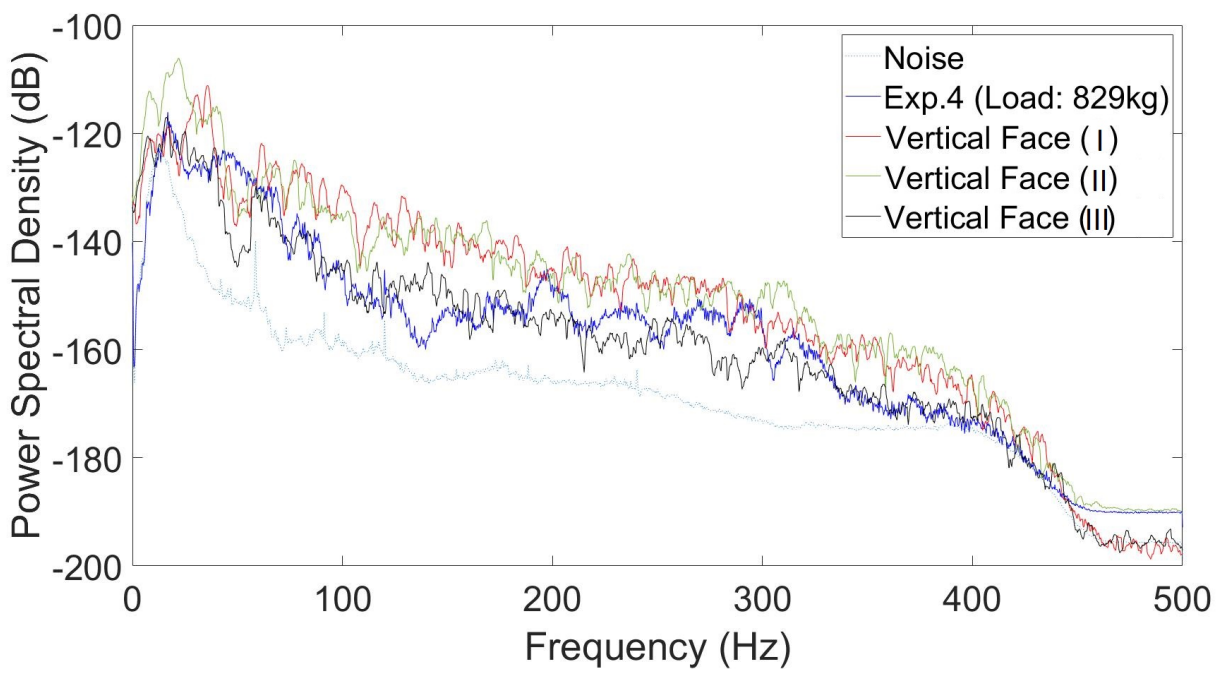

Figure 7: Comparison between emitted energy during Experiment 4 and the induced failure of a $2.5 \mathrm{~m}$ vertical face. For the latter, different modes of failures were observed: I and II - soil block topple and fall, and III - soil block fall. The energy levels of the background noise for the cylinder experiment are also shown. The spectra of Experiment 4 and those of the vertical face are of similar geometries with some differences. The PSDs for the Vertical Face failure has been smoothed with a 10-point moving average for easier comparisons.

The proposed experimental setup and procedure make it possible to investigate different scenarios under controlled conditions that would result in a database to be used for the interpretation of the recordings from an actual landslide, as it allows control over a number of parameters:

(a) The soil type within the cylinder and along the corridor. The soil used in this setup was from the top layer of the investigation site. Material types from other geological layers could also be used to simulate failure events within any geological setting. Use of different soil types in the cylinder and the corridor can simulate friction at the interface between two different geological layers. 
(b) The soil's compaction. Different compaction properties can be used for both soil surfaces involved in the experiment in order to study its effect on the emitted signals.

(c) the stress on the slip surface. By controlling the stress on the slip surface the soil friction at different depths can be simulated.

(d) the saturation conditions. Our experiments were carried out in dry soil. This methodology allows control over a range of degrees of saturation of the soil and their effect on the propagation and attenuation of the seismic waves.

(e) the area of slip surface. Soil displacement can occur at the whole area of the active slope or at smaller ones. Using cylinders of different diameter, the effect of area of the failure plane on the induced seismic signals can be studied.

If the manual reel is replaced with a motorized one, control over the displacement mode could be achieved; a) continuous or discontinuous displacement, b) magnitude of displacement, c) velocity of displacement.

\section{Conclusions}

We present an experimental setup to help in the interpretation of seismic signals induced by landslides in soft soils. The experimental procedure and results are site specific, but the methodology could be duplicated to simulate a range of different conditions. It is a low-cost, fast approach that can provide information on the effect of the on-site soil conditions on the emitted seismic signals and their attenuation over distance, and thus be used for the optimisation of the final design and deployment geometry of the monitoring systems. Most importantly, it can inform signal pattern recognition (data-driven approach) in machine learning algorithms to enable automatic detection and classification of seismic signals emitted during slope failure.

\section{Acknowledgements}

The authors would like to thank prof. Gregório Luís Silva Araújo, prof. Dikran, Jorge de la Rosa Gonzalez, Marcelo Alejandro Lano Serna, Diego Alexander Ocampo, Raydel Lorenzo Reinaldo, Julián Buriticá García, Eduardo Botero, Mr João and Savio, for their assistance during the field experiments. The experimental work in Brasilia was funded by the Civil Engineering department of the University of 
470

471

472

473

474

475

476

477

478

479

480

481

482

483

484

485

486

487

488

489

490

491

492

493

494

495

496

497

498

499

500

501

Brasilia. G.Y. travel and stay in Brasilia were funded by GeoExcel (2009-2015)GEO-engineering EXChanges between Europe and Latin America (FP7-PeopleIRES-2008) and EPSRC grant EP/K005812/1. The seismic monitoring systems were provided by PEG BR - Pool de Equipamentos Geofisicos do Brazil at no cost.

Prof C. Hibert and an anonymous reviewer are thanked for their constructive comments and suggestions.

\section{References}

Amitrano, D., Arattano, M., Chiarle, M., Mortara, G., Occhiena, C., Pirulli, M., Scavia, C. 2010. Microseismic activity analysis for the study of the rupture mechanisms in unstable rock masses. Nat. Hazards Earth Syst. Sci. 10. 831-841. https://doi.org/10.5194/nhess-10-831-2010.

Barla, G.B., Antolini, F., Barla, M., Mensi, E. and Piovano, G. 2010. Monitoring of the Beauregard landslide (Aosta Valley, Italy) using advanced and conventional techniques. Eng. Geol. 116, 218-235. https://doi.org/10.1016/j.enggeo.2010.09.004.

Craig. R.F., 2004. Soil Mechanics, seventh ed. Taylor and Francis Group, Milton. European Academies' Science Advisory Council. 2018. Extreme weather events in Europe: Preparing for climate change adaptation: an update on EASAC's 2013 study. Available at: https://easac.eu/publications/details/extremeweather-events-in-europe/ [last accessed on $7^{\text {th }}$ September 2020]

Gigli, G., Fanti, R., Canuti, P. and Casagli, N. 2011. Integration of advanced monitoring and numerical modeling techniques for the complete risk scenario analysis of rockslides: the case of Mt. Beni (Florence Italy). Eng. Geol. 120, 48-59. https://doi.org/10.1016/j.enggeo.2011.03.017.

Guinau, M., Tapia, M., Pérez-Guillén, C., Suriñach, E., Roig, P., Khazaradze, G., Torné, M., Royán, M.J., Echeverria, A. 2019. Remote sensing and seismic data integration for the characterization of a rock slide and an artificially triggered rock fall. Eng. Geol. 257, 105113. https://doi.org/10.1016/j.enggeo.2019.04.010.

Helmstetter, A., Garambois, S. 2010. Seismic monitoring of Séchilienne rockslide (French Alps): Analysis of seismic signals and their correlation with rainfalls. J. Geophys. Res. 115. F03016. 
Hibert, C., Ekström, G., Stark, C.P. 2014. Dynamics of the Bingham Canyon Mine landslides from seismic signal analysis. Geophys. Res. Lett. 41, 4535-4541. https://doi.org/10.1002/2014GL060592.

Hibert, C., Michéa, D., Provost, F., Malet, J.P., Geertsema, M. 2019. Exploration of continuous seismic recordings with a machine learning approach to document 20 yr of landslide activity in Alaska. Geophys. J. Int. 219(2), 1138-1147. https://doi.org/10.1093/gji/ggz354.

Levy, C., Jongmans, D., Baillet, L. 2011. Analysis of the seismic signals recorded on a prone-to-fall rock column (Vercors massif, Franch Alps). Geophys. J. Int. 186, 296-310. https://doi.org/10.1111/j.1365-246X.2011.05046.x

Mainsant, G., Larose, E., Brönnimann, C., Jongmans, D., Michoud, C., Jaboyedoff, M. 2012. Ambient seismic noise monitoring of a clay landslide: Toward failure prediction. J. Geophys. Res. 117, F01030. Https://doi.org/0.1029/2011JF002159

Petley, D., 2012. Global patterns of loss of life from landslides. Geology. 40(10), 927-930. Https://doi.org/10.1130/G33217.1.

Press, W.H., Teukolsky S.A., Wetterling W.T., Flannery, B.P., 1992. Numerical recipes in C: the art of scientific computing, third ed. Cambridge University Press, Cambridge.

Provost, F., Hibert, C., Malet, J.-P., 2017. Automatic classification of endogenous landslide seismicity using the Random Forest supervised classifier. Geophys. Res. Lett. 44, 113-120. https://doi.org/10.1002/2016GL070709.

Qu, S., Guan, Z., Verschuur, E., Chen, Y., 2019. Automatic high-resolution microseismic event detection via supervised machine learning. Geophys. J. Int. 218(3), 2106-2121. https://doi.org/10.1093/gji/ggz273.

Ritchie, H., Roser, M., 2019. Natural Disasters. Published online at OurWorldInData.org. https://ourworldindata.org/natural-disasters' [Online Resource, accessed on 4 September 2019]

Rothmund, S., Joswig, M., 2012. Investigating Brittle Fracture during Viscous Creep at the Super-Sauze Mudslide by a Comprehensive Field Laboratory, in: Near Surface Geoscience, 18th European Meeting of Environmental and Engineering Geophysics. https://doi.org/10.3997/2214-4609.20143428. 
535

536

537

538

539

540

541

542

543

544

545

546

547

548

549

550

551

552

553

554

555

556

557

558

559

560

561

562

563

564

565

566

567

Sassa, K., Canuti, P., 2009. International Consortium on Landslides, World Landslide Forum, Landslides disaster risk reduction. Springer, Berlin.

Schöpa, A., Chao, W.-A., Lipovsky, B. P., Hovius, N., White, R. S., Green, R. G., Turowski, J. M., 2018. Dynamics of the Askja caldera July 2014 landslide, Iceland, from seismic signal analysis: precursor, motion and aftermath. Earth Surf. Dynam. 6, 467-485. https://doi.org/10.5194/esurf-6-4672018.

Smith, M.J., 1981. Soil Mechanics, fourth edition. Longman, London.

Vilajosana, I., Suriñach, E., Abellán, A., Khazaradze, G., Garcia, D., Llosa, J., 2008. Rockfall induced seismic signals: case study in Montserrat, Catalonia. Nat. Hazards Earth Syst. Sci. 8, 805-812. https://doi.org/10.5194/nhess-8-805$\underline{2008 .}$.

Vouillamoz, N., Rothmund, S., Joswig, M., 2018. Characterizing the complexity of microseismic signals at slow-moving clay-rich debris slides: the supersauze (southeastern france) and pechgrabe (upper austria) case studies. Earth Surf. Dynam. 6(2), 525-550. https://doi.org/10.5194/esurf-6-525$\underline{2018}$.

Walter, M., Joswig, M., 2008. Seismic monitoring of fracture processes generated by a creeping landslide in the Vorarlberg Alps. First break. 26(6), 131135. https://doi.org/0.3997/1365-2397.26.1288.28414.

Walter, M., Arnhardt, C., Joswig, M., 2011. Seismic monitoring of rockfalls, slide quakes, and fissure development at the Super-Sauze mudslide, French Alps. Eng. Geol. 128, 12-22. https://doi.org/0.1016/j.enggeo.2011.11.002.

Welch, P.D., 1967. The use of fast Fourier transform for the estimation of power spectra: a method based on time averaging over short, modified periodograms. IEEE Trans. Audio Electroacoust. 15(2), 70-73. https://doi.org/10.1109/TAU.1967.1161901.

Yfantis, G., 2015. Kinematics of soft soil landslides based on the analysis of microseismic monitoring data. PhD thesis. University of Strathclyde, Glasgow.

Yfantis, G., Carvajal, H.E.M., Pytharouli, S., Lunn, R., 2013. Microseismic Monitoring of Induced Slope Failures at Field Scale, in: EGU General Assembly Conference Abstracts. EGU2013-511. 
568 Yfantis, G., Pytharouli, S., Lunn, R., Carvajal, H.E.M., (under revision). Passive

569 seismic monitoring illuminates phases of slope failure in soft soils. Eng.

$570 \quad$ Geol.

571 Zimmer, V.L., Sitar, N., 2015. Detection and location of rock falls using seismic and 572 infrasound sensors. Eng. Geol. 193, 49-60.

573 https://doi.org/10.1016/i.enggeo.2015.04.007. 